\title{
SELF PERCEIVED HALITOSIS AND ORAL HYGIENE PRACTICE AMONG UNDERGRADUATE AND POSTGRADUATE DENTAL STUDENTS IN HIMACHAL PRADESH
}

\section{Dr Malvika Thakur}

\section{Diksha Wali \\ Bhumika Gupta}

Dr Vikas Jindal

\section{Dr Amit Goel}

\section{Dr Shiva Chauhan}

\section{Dr Shivali \\ Vashisht*}

Sr Lecturer Department of Periodontics, Himachal Dental College, Sundernagar, H.P..

IV Year UG Student, Himachal Dental College, Sundernagar, H.P. .

IV Year UG Student, Himachal Dental College, Sundernagar, H.P.

Professor \& Head Department of Periodontics, Himachal Dental College, Sundernagar, H.P..

Professor Department of Periodontics, Himachal Dental College, Sundernagar, H.P

Sr Lecturer Department of Periodontics, Himachal Dental College, Sundernagar, H.P..

PG Student, Department of Periodontics, Himachal Dental College, Sundernagar, H.P.. * Corresponding Author

ABSTRACT Background- Halitosis is perceptibly unpleasant or offensive odors emanating from the mouth while exhaling during breathing and per se does not imply any particular cause or source. The aim of this study was to estimate the self-reported prevalence and extent of awareness of halitosis among dental students to assess its prevalence, relationship between halitosis and self-reported symptoms of oral health and oral hygiene practices.

Materials And Methods- The Structured questionnaire consisted of 3 parts in which first part was related to gender, age, and educational level, second was participant's perception of any malodor and its history and social effects and third was concerned with oral hygiene practice and health habits and involved dental students from the 5 dental colleges. Out of the 500 questionnaires distributed, 180 were filled and returned with overall response rate of $36 \%$. From these responses, the incomplete questionnaires were discarded and, 152 were selected for analysis. The age range of the participants was between $17-47$ yrs. Females and males accounted for $80.9 \%$ and $19.1 \%$ respectively. The prevalence of self-perceived halitosis was $17 \%$ among the males and $45.5 \%$ among the female participants.

Conclusion-Our results indicate that the prevalence of self-perceived malodor among dental students is in the similar range reported by other studies. However, these findings need to be corroborated by objective examination to ascertain the prevalence.

\section{KEYWORDS :}

\section{INTRODUCTION}

"Ilove bad breath, Said no one ever".

Halitosis is a medical term, first coined by the Listerine Company in 1921, used to describe unpleasant breath, regardless of its sources, oral or non-oral. Etymologically, halitosis is actually a combination of the Latin "halitus", for breath and related to "halare", to breathe and the Greek suffix "osis" to describe a medical condition. Though literally, it means a condition of breath, it is generally understood to mean offensive breath. Other synonyms for this malodorous condition include Foetor oris (Latin "feature," to stink + "oris," oral cavity), ozostomia (Greek "open", to smell + "stoma", mouth), bromopnoea (Greek "bromos," stench + "pnein," to breathe), stomatodysodia (Greek "stoma," mouth + "days," bad + "odoia," condition of odour), bad breath, foul breath and breath malodour.

Halitosis is perceptibly unpleasant or offensive odors emanating from the mouth while exhaling during breathing and per se does not imply any particular cause or source. This interferes with self-confidence and with people's professional and social life ${ }^{1}$. It's no wonder that store shelves are overflowing with gum, mints, mouthwashes and other products designed to fight bad breath. But many of these products are only temporary measures because they don't address the cause of the problem ${ }^{2}$.

Halitosis is not a disease but rather a symptom of underlying oral, systemic or psychological conditions. Knowledge of this condition dates back to ancient cultures. The Talmud, a collection of ancient rabbinical writings dating back more than two millennia, states that bad breath is a major disability. The primary cause of halitosis is due to the release of odoriferous Volatile Sulphur Compounds [VSC] in the exhaled air. VSC are released following putrefactive activity of anaerobic bacteria present in the oral or nasal cavity. The VSC may also be absorbed by the blood stream from a remote part of the body, such as from a cirrhotic liver, and transferred to the pulmonary alveoli to the exhaled through the nostrils or mouth as malodourous breath. If VSC are present in an objectionable concentration in the breath, it is perceived as halitosis ${ }^{3}$. The most commonly identified substances involved are volatile sulphur compounds, methyl mercaptan and hydrogen sulfide. It is very common in the general population and nearly more than $50 \%$ of the general population has halitosis ${ }^{4}$.Halitosis has been associated with plaque, dental diseases, food and beverages, dry mouth, poor oral hygiene and tongue coating etc ${ }^{5}$. It can be classified into several categories: genuine halitosis, which can be physiological or pathological, pseudohalitosis, in which patients think they have bad breath even though they actually do not, and halitophobia, in which people continue to fear that they have bad breath after halitosis treatment ${ }^{6}$. Extraoral causes comprise medication use, psychological factors, and pathologies related to the nose, tonsils, lungs, and stomach? Treatment options, depending on the patient's needs, may be provided by dentists, physicians, psychologists, or psychiatrists.

The importance of halitosis is heavily related to its psychological and social impact ${ }^{1}$.Halitosis affects a person's 
daily life negatively. It has been associated with psychiatric symptoms such as phobias, depression, and can adversely affect self-esteem, self-confidence, and impact on social participation.The present study was done to evaluate selfperception, knowledge, and awareness of oral malodor or halitosis amongst UG \& PG. students studying in various dental colleges of Himachal Pradesh

\section{AIMS \& OBJECTIVES}

This study was conducted to estimate the self-reported prevalence and extent of awareness of halitosis among a sample of undergraduate and postgraduate dental students to assess its prevalence, relationship between halitosis and self-reported symptoms of oral health and oral hygiene practices in the dental students of Himachal Pradesh.

\section{MATERIALS AND METHODS}

\section{Study Population And Recruitment}

This cross-sectional observational study was conducted during the period from November 2019-2020. This study involved dental undergraduate students from the 5 major dental colleges affiliated under Himachal Pradesh University. The questionnaire was distributed to random subjects among dental students of Himachal Pradesh, out of which the participants who responded were 29 males and 123 females. This study was conducted in accordance with the Declaration of Helsinki. Ethical approval was obtained from the Institutional Ethical Committee, Himachal Dental College, Sundernagar.

\section{Structured Questionnaire}

A structured questionnaire was developed in English and tested on a pilot population prior to its administration in this study. The questionnaire was distributed online. The responses were evaluated and modifications were made as required.

The final questionnaire consisted of 3 parts. The first part was related to some socio-demographic factors including gender, age, and educational level. The second part was related to the participant's perception of any malodor (halitosis) and its history and social effects. The third part was concerned with some oral hygiene and health habits. The questions called for a yes/no and sometimes don't know answers. A tick box layout was used for the provision of the appropriate answer. Simple descriptive statistics as frequency distributions and percentages were calculated for the study variables. The relation of the variables with self-perceived halitosis was also evaluated.

\section{QUESTIONNAIRE:}

NAME : AGE:_yrs GENDER:_COURSE:

\section{NAME OF THE COLLEGE :}

1. Halitosis is : $\alpha$ ) Rad Breath b) Foul Taste

2. Is halitosis different from oral malodor: a)yes b) noc)I don't know

3. How often do brush your teeth :

a)occasionally b) once c) twice d) more than twice

4.which secondary method for plaque control do you use: a)mouthwash b) dental floss c)interdental brushes d) none

5 . How do you know you have halitosis?

a)non verbal communication to other people b) someone told me c) i just know d) i don't have halitosis

6) what do you think is the origin of your halitosis a)mouth b)nose c)both d)none
7. Describe your bad breath as precisely as possible ( eg: bitter/burning/foul/flowery/fruity/garlic/rancid/stinky/sweet):

8. When did you first notice you have bad breath:

a) week ago b) months ago c) NA

9. when do you experience your halitosis most often:

a) after awakening b) when i am hungry or thirsty

c) constantly over whole day d) when i talk with other people

e) other f)NA

10. How often do you have halitosis:

a) everyday b) once a week c) NA

11. how intense do you think is your halitosis: a) weak b) average c) intense d) NA

12. What do you think is the commonest cause of halitosis: a) food impaction b) systemic disease c) poor oral hygiene d) caries e) others

13. Do your gums bleed while brushing or eating: a) yes b) no

14. Are there any coatings on your tongue: a) yes b) no c) idon't know

15.Do you smoke?( if yes, how many cigarettes per day)

16. Do you suffer from stress: a) yes b) no c) occasionally

17. Do you keep a particular diet: ( if yes, what?)

18. Do you frequently suffer from cold:

a) yes b) no c)occasionally

19. do you suffer from dry mouth:

a) yes b) noc) occasionally

20. Do you know bad breath is related to systemic diseases (sinusitis/nose problems/stomach problems/lung diseases/ liver diseases):

a) yes b) no

21. Did you consult any doctors ( dentist/general practitioner/ ENT) because of your halitosis:

a) yes b) no

22.Did these doctors prescribe or recommend any medication: a)yes (antibiotics/antacids/mouthwash/lozenges/others.) b) no

23. Does your halitosis affect your social life: ( if yes, in what way)

a) yes, i avoid talking to other people b) yes, i don't like meeting other people

c) yes, i can't start a relationship d) yes other people avoid me e) yes, but my reason isn't listed f) no, it doesn't affect my social life

24. What measures do you use to mask your bad breath: a) chewing b) lozenges c) others d) none

25. Are you aware about methods halimeter, ninhydrin method/electronic nose/ ammonia monitoring) for measuring halitosis?

a) yes b) no

RESULTS

Out of the 500 questionnaires distributed, 180 were filled and 
returned giving an overall response rate of $36 \%$. From these responses, the incomplete questionnaires were discarded and finally, 152 were selected for analysis.

The age range of the participants was between 17-47 yrs. Females and males accounted for $80.9 \%$ and $19 \%$ of the sample, respectively. With regards to education, $84.2 \%$ undergraduate, and the $15.8 \%$ postgraduates. The prevalence of self-perceived halitosis was $17 \%$ among the males and $45.5 \%$ among the female participants.

Table 1: Experience Ābout Halitosis Among Participants

\begin{tabular}{|l|l|l|l|l|}
\hline Experience about halitosis & \multicolumn{2}{|l|}{ MALES(6) } & \multicolumn{2}{l|}{ FEMALES (56) } \\
\cline { 2 - 5 } & YES & NO & YES & NO \\
\hline $\begin{array}{l}\text { Halitosis originating from } \\
\text { nose }\end{array}$ & $0 \%$ & $100 \%$ & $0 \%$ & $100 \%$ \\
\hline halitosis origin from mouth & $66.6 \%$ & 33.35 & $39 \%$ & $61 \%$ \\
\hline $\begin{array}{l}\text { halitosis origin from mouth } \\
\text { and nose }\end{array}$ & $33.3 \%$ & $66.6 \%$ & $30.3 \%$ & $69.7 \%$ \\
\hline $\begin{array}{l}\text { Experiencing halitosis } \\
\text { constantly throughout the } \\
\text { day }\end{array}$ & $0 \%$ & $100 \%$ & $0 \%$ & $100 \%$ \\
\hline $\begin{array}{l}\text { Experiencing halitosis at } \\
\text { particular time of the day }\end{array}$ & $100 \%$ & $0 \%$ & $82.1 \%$ & $17.9 \%$ \\
\hline $\begin{array}{l}\text { Experiencing halitosis } \\
\text { everyday }\end{array}$ & $0 \%$ & $100 \%$ & $5.3 \%$ & $94.7 \%$ \\
\hline $\begin{array}{l}\text { Experiencing halitosis } \\
\text { some days a week }\end{array}$ & $100 \%$ & $0 \%$ & $42.8 \%$ & $57.2 \%$ \\
\hline $\begin{array}{l}\text { I feel about halitosis during } \\
\text { non verbal communication }\end{array}$ & $66.6 \%$ & $33.3 \%$ & $60.7 \%$ & $39.3 \%$ \\
\hline $\begin{array}{l}\text { Others told me I have } \\
\text { halitosis }\end{array}$ & $33.3 \%$ & $66.6 \%$ & $21.4 \%$ & $78.6 \%$ \\
\hline My halitosis is mild & $100 \%$ & $0 \%$ & $94.6 \%$ & $5.4 \%$ \\
\hline My halitosis s intense & $0 \%$ & $100 \%$ & $1.7 \%$ & $98.3 \%$ \\
\hline $\begin{array}{l}\text { Halitosis is affecting my } \\
\text { social life }\end{array}$ & $16.6 \%$ & $33.2 \%$ & $28.5 \%$ & $71.5 \%$ \\
\hline $\begin{array}{l}\text { I have consulted doctor for } \\
\text { halitosis }\end{array}$ & $16.6 \%$ & $33.3 \%$ & $16 \%$ & $84 \%$ \\
\hline $\begin{array}{l}\text { I use mouth fresheners } \\
\text { (chewing gum, lozenges) to } \\
\text { prevent halitosis }\end{array}$ & $83.3 \%$ & $16.7 \%$ & $83.9 \%$ & $16.1 \%$ \\
\hline
\end{tabular}

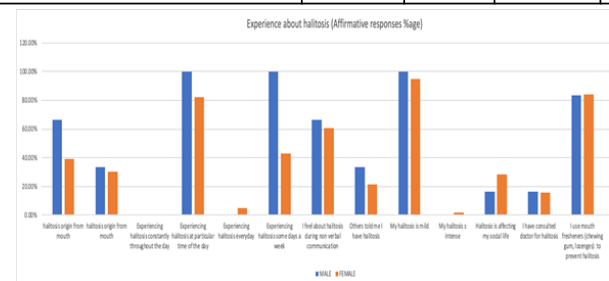

Figure 1: Experience About Halitosis Among Participants

Tablel \& Figurel shows the experience about halitosis among participants. It depicts that $100 \%$ of males experienced halitosis some days a week, at particular time of day and with intensity being mild and none of the participants experienced it on a daily basis.

In females, $39 \%$ of them thought origin of halitosis to be mouth while $30.9 \%$ of females thought its origin to be from both nose and mouth.

In our survey, it was seen that $16 \%$ of males and females have consulted the doctor regarding this problem and among 16$30 \%$ of the participants this problem has affected their social life. Almost equal percentage of males and females stated they use mouth fresheners to cure halitosis $(\sim 80 \%)$.

Table 2: Knowledge Ābout Halitosis Among The Participants

\begin{tabular}{|c|}
\hline KNOWLEDGE LEVEL \\
\hline \\
\hline
\end{tabular}

\begin{tabular}{|l|l|l|l|l|}
\hline $\begin{array}{l}\text { Halitosis is related to bad } \\
\text { breath }\end{array}$ & $100 \%$ & $0 \%$ & $100 \%$ & $0 \%$ \\
\hline $\begin{array}{l}\text { Halitosis is related to foul } \\
\text { taste }\end{array}$ & $0 \%$ & $100 \%$ & $0 \%$ & $100 \%$ \\
\hline $\begin{array}{l}\text { Halitosis is different from } \\
\text { malodour }\end{array}$ & $51.7 \%$ & $48.2 \%$ & $26 \%$ & $74.7 \%$ \\
\hline $\begin{array}{l}\text { Halitosis is related to } \\
\text { systemic disease }\end{array}$ & $89.6 \%$ & $10.3 \%$ & $78 \%$ & $21.9 \%$ \\
\hline $\begin{array}{l}\text { Food impaction is the } \\
\text { common cause of halitosis }\end{array}$ & $0 \%$ & $100 \%$ & $13.8 \%$ & $86.2 \%$ \\
\hline $\begin{array}{l}\text { Poor oral hygiene is the } \\
\text { common cause of halitosis }\end{array}$ & $82.7 \%$ & $17.2 \%$ & $65 \%$ & $35 \%$ \\
\hline $\begin{array}{l}\text { Caries is the common cause } \\
\text { of halitosis }\end{array}$ & $13.7 \%$ & $86.2 \%$ & $0 \%$ & $100 \%$ \\
\hline $\begin{array}{l}\text { Systemic disease is the } \\
\text { common cause of halitosis }\end{array}$ & $3.4 \%$ & $96.5 \%$ & $9.7 \%$ & $90.3 \%$ \\
\hline
\end{tabular}

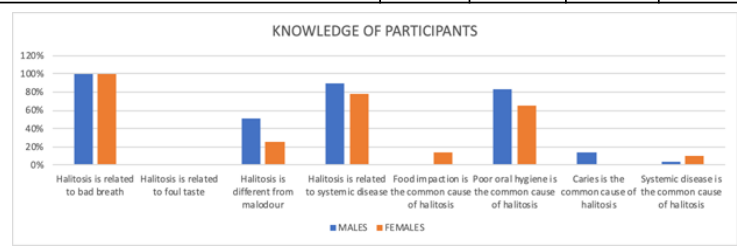

Figure 2: Knowledge About Halitosis Among The Participants

Table 2 \& Figure 2 depicts knowledge about halitosis among participants out of which all males and females agreed to the fact that halitosis is related to bad breath contributing to about $100 \%$ while $0 \%$ of males and females considered halitosis to be related to foul taste. In this survey, $82-90 \%$ of males said that systemic diseases and poor oral hygiene is the commonest cause of halitosis and females stated $78 \%$ and $65 \%$ respectively for the same.Also it is seen that less than $10 \%$ of males and females have a knowledge about food impaction and caries to be the cause of halitosis.

Table 3: Oral Hygiene Practices Among Participants

\begin{tabular}{|l|l|l|l|l|}
\hline \multirow{2}{*}{$\begin{array}{l}\text { Personal hygiene based } \\
\text { question }\end{array}$} & \multicolumn{3}{|l|}{ MALES(29) } & \multicolumn{2}{|l|}{ FEMALES(123) } \\
\cline { 2 - 5 } & YES & NO & YES & NO \\
\hline Occasional teeth brushing & $0 \%$ & $100 \%$ & $0 \%$ & $100 \%$ \\
\hline Teeth brushing once & $13.7 \%$ & $86.2 \%$ & $28.4 \%$ & $71.5 \%$ \\
\hline Teeth brushing twice or more & $86.2 \%$ & $13.7 \%$ & $71.5 \%$ & $28.4 \%$ \\
\hline $\begin{array}{l}\text { Mouthwash as secondary } \\
\text { method of plaque control }\end{array}$ & $79.3 \%$ & $20.6 \%$ & $60.1 \%$ & $39.8 \%$ \\
\hline $\begin{array}{l}\text { Dental floss as secondary } \\
\text { method of plaque control }\end{array}$ & $17.2 \%$ & $82.7 \%$ & $18.6 \%$ & $81.3 \%$ \\
\hline $\begin{array}{l}\text { Interdental brush as } \\
\text { secondary method of plaque } \\
\text { control }\end{array}$ & $0 \%$ & $100 \%$ & $7.3 \%$ & $92.6 \%$ \\
\hline $\begin{array}{l}\text { No method used as } \\
\text { secondary method of plaque } \\
\text { control }\end{array}$ & $3.4 \%$ & $96.5 \%$ & $13.8 \%$ & $86.1 \%$ \\
\hline
\end{tabular}

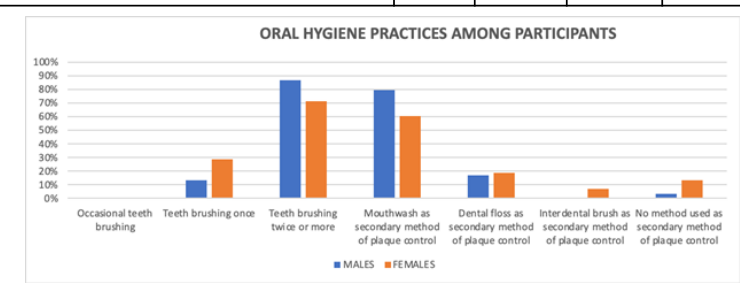

Figure 3: Oral Hygiene Practices Among Participants

Table 3 \& Figure 3 is based on oral hygiene practices among participants in which it is seen that $86.2 \%$ of males and $71.5 \%$ 
of females brush their teeth twice a day. And out of the secondary methods used for plaque control , use of mouthwash contributing to about $79.3 \%$ in males and $60.1 \%$ in females which means that this practice is highly prevalent while the use of dental floss is less than $20 \%$ among the participants. And the use of interdental brushes as a secondary method of plaque control is very minimal among males and females accounting to about less than $8 \%$ of the total.

Table 4: Symptoms Among Participants

\begin{tabular}{|l|l|l|l|l|}
\hline \multirow{2}{*}{ SYMPTOMS } & MALE (29) & \multicolumn{2}{l|}{ FEMALE (123) } \\
\cline { 2 - 5 } & YES & NO & YES & NO \\
\hline Tongue coating & $3.4 \%$ & $96.5 \%$ & $5.6 \%$ & $94.3 \%$ \\
\hline Cold & $34.4 \%$ & $65.5 \%$ & $58.2 \%$ & $41.7 \%$ \\
\hline Dry mouth & $13.7 \%$ & $86.2 \%$ & $31.7 \%$ & $68.2 \%$ \\
\hline Stress & $41.3 \%$ & $58.6 \%$ & $65.8 \%$ & $34.1 \%$ \\
\hline Gum bleeding & $3.4 \%$ & $96.5 \%$ & $3.2 \%$ & $96.7 \%$ \\
\hline
\end{tabular}

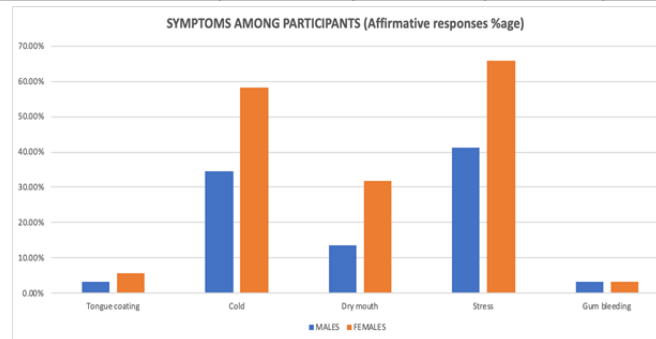

Figure 4: Symptoms Āmong Participants

Table 4 \& Figure 4 is about symptoms seen among males and females. Following are some of the symptoms covered in our survey which includes tongue coating, cold, dry mouth, stress and gum bleeding. The major symptoms seen are cold and stress with $34.4 \%$ and $41.3 \%$ in males and $58.2 \%$ and $65.8 \%$ in females respectively. The minor symptoms seen among participants are tongue coating and gum bleeding contributing to about less than $5 \%$ of total. Xerostomia that is dry mouth a symptom which is seen in $13.7 \%$ of males and $31.7 \%$ of females

Table 5: Smoking Status Of Participants

\begin{tabular}{|l|l|l|}
\hline Smoking status & MALES(29) & FEMALES(123) \\
\hline Smoker & $6.8 \%$ & $0.81 \%$ \\
\hline Non smoker & $93.1 \%$ & $99.1 \%$ \\
\hline
\end{tabular}

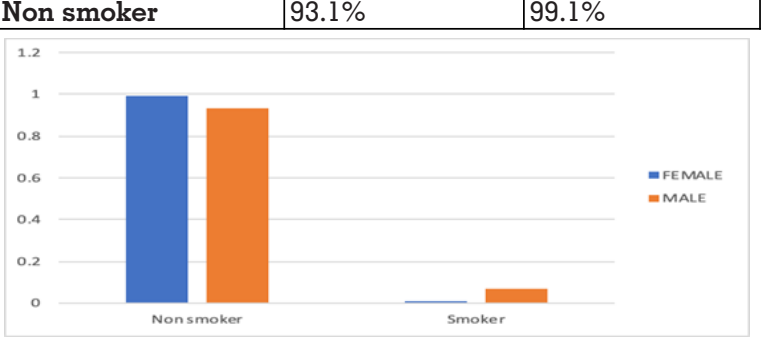

Figure 5: Smoking Status Of Participants

Table 5 \& Figure 5 gives the smoking status of participants. The smoking status is that more than $90 \%$ of participants are non smokers while smokers contributing to about $6.8 \%$ in males and $0.81 \%$ in females.

\section{DISCUSSION}

Halitosis, often called bad breath or oral malodor, is a common condition with an estimated prevalence of $10-30 \%{ }^{8}$ A recent research project demonstrated that halitosis is a highly unattractive aspect in social interactions. Nearly $40 \%$ of 1006 members of an online panel reported halitosis to be the strongest "downer" when meeting a person for the first time. The problem of persons with halitosis is that the halitosis may remain unnoticed because people generally are not aware of the quality of their own oral odor. Interestingly, if people are requested to judge their own oral odor, only a relatively small group of about five per cent indicates to suffer from halitosis. ${ }^{10}$

The objective of the present study was to determine the prevalence of halitosis among dental students using a questionnaire and evaluating awareness regarding oral hygiene. The study also aimed to relate various factors such as gender, course and age predilection, time of occurrence, physiological factors like tongue coating, psychological factors, habits, pathology and other systemic diseases with halitosis. Questions related to the above-mentioned topics were included to relate halitosis to these factors. The presence or absence of halitosis is often discerned by individuals on their own. The etiology could be either intraoral or extraoral causes. The diagnosis is usually subjective as there are no standard criteria that define a patient with halitosis.

This study shows that prevalence of self-perceived halitosis is more in females (56 females out of 123 which is $45.5 \%$ and 6 males out of 29 which is $20.6 \%$ ). This can be attributed to Volatile Sulphur compounds (responsible for halitosis), which are higher in females and salivary flow rate lower during the menstrual and premenstrual phases compared to the follicular phase. In accordance with the study by PO Lima, CM Calil, FK Marcondes (2013) ${ }^{11}$, who in their study concluded that the production of VSC is influenced by the menstrual cycle and protein concentration and salivary flow might be involved in this process of halitosis and this could imply a more conscious attitude among females than among males. Contrary to our study, Halitosis shows a slight male predilection which coincides with studies done by Andrea Almas K, Al- Hawish K(2003) and Andrea Z, Marja LL, Andrea F (2016).

As it is already stated, oral malodor is a physiological condition that originates in the oral cavity and is not caused by any specific disease or pathologic condition, the primary origin is likely to be dorsum of the tongue. Whereas halitosis is a pathological condition caused by disease or pathologic processes related to the oral cavity. ${ }^{12}$ Our study showed that less than half of the participants knew that halitosis is different from oral malodor. Whereas, in general the knowledge of halitosis among the males was $100 \%$ and they stated that halitosis is related to systemic disease and 5 out of 6 which is $83.3 \%$ stated that the poor oral hygiene is the commonest cause of halitosis. There can be many causes of halitosis like food impaction, caries, poor oral hygiene, systemic diseases etc. Most common cause is poor oral hygiene which is stated by almost $80 \%$ of participants, reason being when a person does not brush or floss his/her teeth regularly, food particles remaining in the mouth can rot and cause bad odors. Poor dental care can lead to a buildup of plaque in the mouth, which causes an odor of its own. If oral hygiene is already good, or improves and yet oral malodor persists, the tongue may be the likely source of odor. ${ }^{13}$

As in our study the participants who reported self-perceived halitosis, $100 \%$ of the males and $94.6 \%$ of the females reported mild halitosis, this can be attributed to the fact that the participants did not use dental floss and interdental cleaning aids as secondary method of plaque control.The other reason could be tongue coating as there is a positive correlation between the oral malodor and the levels of VSCs on the dorsum surface of the tongue and the propensity of microorganisms colonized on the surface of the tongue itself. A recent systematic review concluded that tongue scraping may have a limited benefit in reducing oral malodor in the long term.

Apart from intraoral causes halitosis can also be caused by 
extra oral causes such as systemic diseases which include ENT diseases, gastrointestinal disease, liver disease, kidney disease, systemic metabolic disorders like uncontrolled diabetes mellitus because of accumulation of ketones, trimethylaminuria and hormonal causes. A study done by Shuji Awano et al. $(2008)^{17}$ established a significant relationship between volatile sulfur compounds (VSCs), including hydrogen sulphide, methyl mercaptan $\left(\mathrm{CH}_{3} \mathrm{SH}\right)$ and dimethyl sulphide in mouth air of patients and a history of systemic disease such as hypertension as well as respiratory, cerebrovascular and liver diseases.

As reported in our study the prevalence of good oral hygiene habits among dental students was very encouraging. In our study, participants who brushed their teeth before going to bed had a significantly lower prevalence of halitosis compared to those who did not brush their teeth before going to bed. The oral hygiene habits were excellent among the students with most of the students reporting brushing twice daily. In our study $100 \%$ of the males brushed their teeth twice a day and $64.2 \%$ of females brushed their teeth twice a day. Effective brushing and flossing can significantly reduce halitosis, especially in people with poor oral hygiene and related gingival and periodontal disease. It may be considered that a major reduction in microbial plaque in participants who brushed their teeth before going to bed will result into a lower total number of the microbes responsible for halitosis and its intensity bearing in mind that one microbe in 24 hours multiplies after every 3 hours and ends up in totaling into $254 .^{12}$

In this study it was found that approximately $58.2 \%$ and $65.8 \%$ of the females felt that they suffered from halitosis when they suffered from cold or stress respectively, while the males reported were $34.4 \%$ and $41.3 \%$ for cold and stress respectively. The reason could be colds, allergies or bacterial infections due to post-nasal drips. When this excess mucus occurs, it creates a ripe environment for bacteria to multiply, giving the discharge an odor and hence bad breath. During stress, the sympathetic system is activated which leads to reduced salivary flow leading to halitosis. It is also found that anxious situations increase VSC concentration therefore leading to halitosis. ${ }^{14}$ In case of Hunger or fasting, the mechanical action of tongue is reduced leading to less cleansing action and the salivary flow rate is decreased causing xerostomia/dry mouth In this study, symptoms among the male participants were $3.4 \%$ tongue coating, $13.7 \%$ dry mouth, $3.4 \%$ gum bleeding and females accounting to $5.6 \%, 31.7 \%$ and $3.2 \%$ respectively, This can be attributed due to the reason because the surface of the tongue has innumerable depression where bacterial adhesion and growth occurs. Food particles and desquamated epithelial cells accumulate which tend to be consequently putrefied by the bacteria. Fissures and crypts of the tongue harbors large number of micro-organism which includes Prevotella (Bacteroides) melaninogenica, Treponema denticola, Porphyromonasgingivalis, Porphyromonasendodontalis etc. Proteolytic activity by microorganisms residing on the tongue and teeth results in foul-smelling compounds, and is the most common cause of oral malodor. Individuals with a healthy periodontium can show halitosis caused by the impaction of food, bacteria, leukocytes and desquamated epithelial cells on the dorsum of their tongue. A reduced saliva flow during sleep favours anaerobic bacterial putrefaction, giving rise to so-called "morning breath,"15

Smoking reduces olfactory sensitivity thus impairing individual's ability for self-perception of halitosis. In the present studied population smoking habits ranged from 0.81 $6.8 \%$ among females and males, respectively. In a previous study the smoking habits of the male student was $10 \%$. Health workers should serve as a role model of good health for others.
The $6.8 \%$ smokers found among male students is high for this point in their professional careers. The habit should be discouraged as much as possible. There should be organized efforts and support for students to quit smoking as soon as possible. Our results are in accordance with the study, conducted by Mehta S P et al (2017) ${ }^{13}$ who concluded that the relation between smoking and tobacco consumption and halitosis could not be significantly established. On the contrary Al-Atrooshi and Al-Rawi stated the Smoking and tobacco are an important extrinsic etiology for halitosis.

According to our knowledge, this is the first study which is conducted among Dental college students (undergraduates and postgraduates) regarding self-perceived halitosis in the Himachal Pradesh region. Literature reveals that the prevalence of halitosis ranges to around $50 \%$ in the USA, $27.5 \%$ in China, and $22 \%$ in France. This highlights the significance of halitosis as a widespread global problem. It has been estimated that in the developed world, 8 to $50 \%$ of people perceive oral halitosis. ${ }^{16}$ Perception of halitosis may differ in line with the subjectivity of perception. The lack of correlation of self-perceived oral malodor with clinical or laboratory-based evaluationis the main limitation of our study and the results were purely based on the perception of the students.

\section{CONCLUSION}

Our results indicate that the prevalence of self-perceived malodor among dental students is in the similar range reported by other studies. However, these findings need to be corroborated by objective examination to ascertain the prevalence.

In recent years the etiology of halitosis has become increasingly clear, and it is now known that halitosis originates more from within the oral cavity than elsewhere in the body. Therefore, more than any other health professional, dentists ought to be well informed on halitosis in order to provide effective treatment and proper advice to the significant proportion of the general population affected by this condition. Therefore the role of dental professionals in maintaining good oral health should be emphasized in the community. The awareness of halitosis as an individual entity should be promoted to the general population and the therapeutic measures should be made available to all.

\section{REFERENCES}

1. Mubarak AB, Hamdan RA, and Shriya RA. Self-perception, knowledge, and awareness of halitosis among female university students.ClinCosmet Investig Dent. 2017; 9: 45-52.

2. Mayo Foundation for Medical Education and Research (MFMER).Bad breath,3/10/2018.

3. Gnanasekhar JD. Aetiology, Diagnosis and Management of Halitosis- a Review. Perio 2007;4(3):203-214.

4. Aylıkçı BU \& Çolak H. Halitosis: From diagnosis to management .J Nat Sci Biol Med. 2013 Jan-Jun; 4(1): 14-23.

5. Porter SR \& Scully C .Oral malodour (halitosis).BMJ. 2006 Sep 23; 333(7569): 632-635.

6. Yaegaki $\mathrm{K}$ and Coil JM. Genuine halitosis, pseudo-halitosis, and halitophobia: classification, diagnosis, and treatment. Compendium of continuing education in dentistry (Jamesburg, N.J.: 1995) 21(10A):880-6, 888-9; 890 November2000

7. Kuzhalvaimozhi P and Krishnan M. Self-Perception, Knowledge and Attitude of Halitosis among patients attending a Dental Hospital in South India-A Questionnaire Based Study.2019; 12(1)

8. Scully C, Greenman J. Halitosis (breath odor). Periodontol. 2008;48:66-75.

9. De Jongh A, van Wijk AJ, Horstman M, de Baat C. Attitudes towards individuals with halitosis: an online cross sectional survey of the Dutch general population. Br Dent J. 2014;216, E8.

10. Bornstein MM, Kislig K, Hoti BB, Seemann R, Lussi A. Prevalence of halitosis in the population of the city of Bern, Switzerland: a study comparing selfreported and clinical data. Eur J Oral Sci. 2009;117:261-7.

11. Lima, P. O., Calil, C. M., \& Marcondes, F. K. (2013). Influence of gender and stress on the volatile sulfur compounds and stress biomarkers production. OralDis, 19(4), 366-373.

12. Ashwath B, Vijayalakshmi R, and Malini S. Self-perceived halitosis and oral hygiene habits among undergraduate dental students. J Indian Soc Periodontol. 2014 May-Jun; 18(3): 357-360.

13. Mehta S.P (2017) Self-Perceived Halitosis amongst School, Junior College and Dental College Students in Navi Mumbai Region- 'a Kap Survey'. J Dent 
Treat Oral Care 2(1): 101

14. Kayombo CM and Mumghamba EG. Self-Reported Halitosis in relation to Oral Hygiene Practices, Oral Health Status, General Health Problems, and Multifactorial Characteristics among Workers in Ilala and Temeke Municipals, Tanzania.Int J Dent. 2017; 2017: 8682010.

15. Setia S, Pannu P and Sofat A. Correlation of oral hygiene practices, smoking and oral health conditions with self-perceived halitosis amongst undergraduate dental students. J Nat SciBiol Med. 2014 Jan-Jun; 5(1): 67-72.

16. Almas K, Al-Hawish A, Al-Khamis W. Oral Hygiene Practices, Smoking Habits, and Self-Perceived Oral Malodor Among Dental Students. J Contemp Dent Pract 2003 November; (4)4:077-090.

17. S Awano et al. Relationship between volatile sulfur compounds in mouth air and systemic disease. J. Breath Res. 2 (2008). 